\title{
Empirical Study on 3R Strategies in Foreign Language Education
}

\author{
Liu Zheng-xia \\ Faculty of Foreign Language Studies; Huaiyin Institute of Technology HYIT; Huai’an Jiangsu , PRC \\ Email: liu4931520@126.com
}

\begin{abstract}
Keywords:3R strategies; foreign language education; resource strategy; response strategy; retention strategy
\end{abstract}

Abstract: Foreign language learning strategies are attracting the interest of researchers, but the relationship between strategy use and language proficiency is complex. Based on the empirical study, a theory of 3R strategies, i.e. resource strategy based on the sensory system, response strategy on motor system, and retention strategy on the memory system , is presented to fit into foreign language education. 3R strategies are regarded as one of the most important methods in increasing learners efficiency and the corresponding variables have been proved to be of a great educational significance in language teaching and learning process.

\section{Introduction}

Nowadays, institutions of higher education across the nation are faced with political, economic, social and technological pressures to be more responsive to learners' needs and more concerned about how well they get accustomed to the future society. Therefore, language education itself has to change in order to connect with the increasingly developing situation. It is challenging for schools and teachers to keep up with the current teaching technology in order to educate their students.

Learning strategies for foreign language education are attracting the interest of researchers. More proficient learners tend to use a wider range of strategies, but the relationship between strategy use and language proficiency is complex. This article, based on the empirical study, attempts to present a theory of 3R strategies, i.e. resource strategy, response strategy, and retention strategy, to fit into the foreign language education. 3R strategies are regarded as one of the most important methods in increasing learners efficiency and the variables have been proved to be of a great educational significance in language learning process. It is time to think differently about assessing the role of $3 \mathrm{R}$ technology and the corresponding variables in foreign language teaching and learning process.

\section{Definition and classification of learning strategies}

Foreign language education involves a conjunction of a variety of internal and external factors. It is vital to investigate into the cultural, social, economic and technological aspects in learning strategies. The study of learning strategy is a prominent topic both in the fields of education and linguistics. However, there is no universal conception on its definition and classification both inside and outside China. Rubin (1975), one of the first researches in this field, defines learning strategies as "the techniques or devices which a learner may use to acquire knowledge". She divides the learning strategies into two kinds: Direct learning strategies include clarification, deductive reasoning, and practice, and indirect learning strategies include creating opportunities for practice and production tricks. Edwards (1997) views strategies for learning as "devices for compensating for inadequate resources" . He argues that it is even possible that successful use of communication strategies may actually prevent language learning since skillful compensation for lack of linguistic knowledge may obviate the need for learning. Oxford et al. $(1990,1993)$ argue that language learning strategies are the conscious steps or behaviors used by language learners to enhance the acquisition, storage, retention, recall, and use of information.

\section{R Strategies in Essence}

The models above outline an exhaustive category of learning strategies, but there exists some overlapping between the concepts. It is necessary for researchers to specify a simplified and feasible strategy for tutors to apply to foreign language education. It is also clear that students can be taught to use better strategies to improve language performance. By definition, 3R strategies refer to the resource strategy, response strategy, and retention strategy in learning process. Resource learning 
strategy, related to the sensory system, refers to the variety of information that learners are confronted with in the learning process. Individuals are not merely determined by his mental representations but also the external mechanism in the real life. The accumulation of knowledge both from the internal and external perception, varying from person to person, eventually constitutes the resource learning strategy. It would be helpful to build a virtual environment for the learners to practice language from the sensory system. Response learning strategy, related to the motor system, includes two important issues: 1) interaction and control, 2) autonomy and detachment. Language education involves cooperation between tutors and apprentice, learners and materials, and learners themselves. It represents the interactions between body and the sensory information from the motor system. The interactive process depends mostly on the tutors control over learners and their resources available. This strategy helps to construct a virtual language learning environment to motivate learners to join in the education practice and to show his initiatives and activeness. The third retention strategy, in relation to the knowledge based on the applying of resource and response educational strategy appropriately to the teaching-learning process, discusses the learnercentered principles as a framework. It considers the implications of the memory system for the application of technology to support language education in service to learners and learning, building learner-centered learning communities, and transforming the educational system into a neural process. This topic has been partially approached during the course of language education, and the function of retention strategy on neural system will be eventually mapped and understood in the near future.

\section{Empirical study on 3R strategies}

Researchers and experts put more emphasis on the roles of learning strategies in improving language proficiency. However, instructional technology is less stated from the teachers' perspective. Since the importance of learning strategies has been recognized, it is necessary for scholars to conduct a study on the variables concerning foreign language education. Thus, the empirical study on 3R strategies are presented for filling the gap between the learning strategies and their variables.

\section{Research design}

1) In this study, some teaching variables are explored to research the teachers' role and learners' engagement in language education practice. A questionnaire and a contrast experiment are designed to discover the instructional needs in classroom. The subjects include 200 first-year and second-year non-English major students from four different departments in Huaiyin Institute of Technology. All the subjects are pursuing English learning at present, with half of them from liberal arts and half from science majors. They are divided into two groups, one control and the other experimental group. All of them participate in the questionnaire and four fail to answer the questionnaire completely. The results of participants in the study is presented in the following table.

Table 1: Basic Information for Subjects

\begin{tabular}{|l|l|l|l|}
\hline Number & Gender & Major & Grade \\
\hline 100 & Male & Liberal Arts & Freshmen \\
\cline { 2 - 3 } & & & \\
\hline \multirow{2}{*}{100} & Female & Science & \\
\cline { 2 - 3 } & Male & Sciences & Sophomores \\
\cline { 2 - 3 } & Female & Liberal Arts & \\
\hline
\end{tabular}

\section{Research method}

The first method used in this study is a questionnaire, which is composed of three parts. The first ten questions concern the subjects' background information, such as age, sex, interest, major, grade, and native language; The second part aims at discovering the subjects' learning strategies and motivations for learning foreign language. The third part emphasizes the variables in language education, including learning methods, teaching effects, learning materials, and feedback on foreign language learning, etc. All the items are designed on the rate of five-point Likert scale for easy reference. Most important of all, instructions are listed in detail before the questionnaire. 
The second approach involves a long-term contrast experiment between the control group and the experimental group. Both are tested for English listening proficiency at the beginning of the experiment, and then the control group is tutored in terms of the conventional strategies while the experimental group is designed to put 3R strategies into language education practice. Both groups are entitled to the same teacher, shared materials and equal chances to practice. After a three-month period, subjects from both groups are tested again for their listening proficiency. After transformed into statistical data, all the data are input into the computer with SPSS(Statistical Package for Social Science for windows) 11.5 to be analyzed by the bivariate Pearson Correlation analysis.

\section{Results and discussion}

According to the data analysis, the subjects obviously tend to fall into two obviously genderrelated categories, which can be seen in Table 2. Namely, 30\% subjects participating in the questionnaire tend to approve of the traditional learning strategies. Girl students argue for the lecturer-centered learning strategies, such as the motivation strategy, classroom management, questioning, evaluation/assessment strategies, and vocabulary/grammar strategies. In other words, teachers are making their every effort to explain and learners are sitting quietly. It is the commonest and most traditional way of teaching and learning. Though teachers always try to find the most effective way of working, they still follow certain principles and strategies. Instead, they use similar strategies class after class and respond in similar ways to recurring classroom situations. The rest $70 \%$ of the subjects are ready to try the 3R strategies in learning foreign language. Most boy students are more likely to adopt the resource strategy to apply what they learn in the classroom to real-life experiences, which engages students in active discussion about issues and problems inherent in practical application. It can highlight fundamental dilemmas or critical issues and provide a format for role playing ambiguous or controversial scenarios. $50 \%$ subjects argue for the response strategy, which shows that learning is enhanced when students become actively involved in the learning process and engages students in the learning process to stimulate critical thinking and a greater awareness of other perspectives.

Table 2: Statistical Data for the Questionnaire

\begin{tabular}{|l|l|l|l|}
\hline \multicolumn{2}{|l|}{ Strategies } & Gender & Percentage \\
\hline \multirow{2}{*}{$\begin{array}{l}\text { Tradit } \\
\text { ional }\end{array}$} & Lectured-centered & Girl students & $25 \%$ \\
\cline { 2 - 4 } & Learner-centered & Boy students & $5 \%$ \\
\hline \multirow{2}{*}{$3 R$} & Resource & Girl students & $20 \%$ \\
\cline { 2 - 4 } & Response/Retention & Boy students & $50 \%$ \\
\hline
\end{tabular}

In the contrast study, data analysis presents a similar result. In the control group, $15 \%$ of the subjects, who follow the tutor-centered strategy, got a higher score than that they did three months before. $75 \%$ of the students scored an equal or lower mark. In the experimental group, $80 \%$ scored higher than before. They reported that they can comprehend the test materials from a new perspective by applying 3R strategies in language learning process. The rest scoring lower explain that they are accustomed to the traditional style.

The results of the research show that the effect of language education involves learning strategies, individual efforts, and appropriate tutor's help. Thus it can be seen that the three variables work on the language proficiency together while learning strategy has much more genderrelated tendency. Therefore, scientific strategies adjust learners to a newly developed language environment, encourage them to enter a brand-new learning atmosphere, and master a different language with efficiency. New technology has made it possible for learning experiences to be extended beyond the confines of the traditional classroom. 


\section{Summary}

Learning strategies are regarded as a vital part in education and no exception in contributing to language education. Successful use of learning strategies increases learners' interest in language, produces teaching effectiveness, and hence promotes language proficiency. 3R strategies provide a new insight into foreign language education based on the researches into the sensory system, the motor system and the memory. In terms of tutors, novelty and originality invite challenge and opportunity, which involve more resources, stimulus and interactions in teaching process. In terms of learners, the routine classroom is inadequate for real-life communication, so it is high time to adapt to the increasingly developed classroom atmosphere. Researchers themselves need to immerse themselves into more strategies just to keep pace with the changing surroundings. The world is changing quickly and only by way of education technology do we stand a chance of not being left behind in foreign language education.

\section{References}

[1] A. Giddens, Modernity and Self-identity. Self and Society in Late Modern Age. Cambridge: Polity Press, 1991.

[2] D. J. Young, \& R. L. Oxford, A Gender-related Analysis of Strategies Used to Process Written Input in the Native Language and a Foreign language. Applied language learning, 1997, pp:4373.

[3] D. Edwards, Discourse and Cognition. London, Sage,1997.

[4] Gui Shichun, English-learning Psychology of Chinese Students. Changsha: Hunan Education Press, 1991.

[5] J. Rubin, What the “Good Language Learner” Can Teach Us. TESOL Quarterly,1975, pp:41-51.

[6] J. Sullivan, Comparing Strategies of Good and Poor Comprehenders. Journal of Reading, 1978, pp:710-715.

[7] K. A. Bruffee, Collaborative Learning. Higher Education, Interdependence, and the authority of Knowledge. Baltimore and London, The Johns Hopkins University Press, 1993.

[8] K. Kuutti, Activity Theory as a Potential Framework for Human-computer Interaction. Cambridge, MA, MIT, Press,1996.

[9] R. L.Oxford, Language Learning Strategies: What Every Teacher Should Know. Rowley, Mass.: Newbury House,1990. 